\title{
AÇÃO COMUNICATIVA E FILOSOFIA DA LIBERTAÇÃO COMO UTOPIA Uma análise comparativa de Jürgen Habermas e Enrique Dussel
}

\author{
Emil Albert Sobottka
}

\begin{abstract}
SINTESE - A Teoria da Açăo Comunicativa e a Filosofia da Libertação são analisadas comparativamente com base em elementos da teoria de Karl Mannheim sobre ideologia e utopia. Os elementos contrapostos são os seguintes: a avaliação da realidade atual, a nova realidade utópica projetada, a conceitualização das condições teóricas e das condições práticas, bem como a definição dos portadores da mudança social. Uma teoria elaborada da ação social e da sociedade, mas de capacidade explicativa restrita à sua situação de origem, em Habermas, contrasta-se em Dussel com a aguçada elaboração de categorias para a análise dos mecanismos econômicos de dominação locais e internacionais, associada à ausência de uma teoria que permita operacionalizar alternativas de mudança social efetiva. Daí deriva-se a pergunta pela possibilidade de uma síntese (complementaridade) destas perspectivas.
\end{abstract}

ABSTRACT - Based on the theory by Karl Mannheim about ideology and utopia, the author makes a comparison between the theory of communicative action and the philosophy of liberation. The evaluation of the actual reality, the new projected utopic reality, the conceptualization of the theoretic and the practical conditions, as well as the definition of the subjects of the social change are opposed. He defends that Habermas' elaborated theory of social action and society is restricted in its explaining capacity to the society in which it was originated. It contrasts with Dussel's keen elaboration of categories for the analysis of the economic mechanisms of local and international domination. But Dussel's work lacks a social theory, which allows to realize alternatives of social change. Out of this contrast he derivates the question about the possibility of a synthesis of both perspectives.

\section{Introdução}

No presente trabalho são comparadas a teoria da ação comunicativa, de Jürgen Habermas, e a filosofia da libertação formulada por Enrique Dussel com base na utopia de uma nova sociedade. As duas teorias se originam de contextos bem

\footnotetext{
O presente artigo é uma síntese revisada de nossa dissertaçäo de mestrado, apresentada em abril de 1992 no Instituto de Filosofia e Ciências Humanas da Universidade Federal do Rio Grande do Sul, em Porto Alegre, sob a orientação do Prof. Dr. Enno Dagoberto Liedke Filho.
} 
distintos, mas são por seus autores vistas como instrumento para a superação de realidades em suas respectivas sociedades, tidas por eles como insatisfatórias.

Tanto Habermas como Dussel estão na tradição de uma teoria crítica da sociedade que tem suas raízes no marxismo, mas permaneceu aberta a outras influências. Na comparação de suas teorias queremos perguntar por semelhanças e diferenças mas principalmente perseguir a pergunta sobre a possibilidade de uma mútua complementação destas teorias. Esta pergunta surgiu não só porque em leituras preliminares havíamos encontrado semelhanças que convidavam a uma comparação, mas também porque freqüentemente suspeitamos haver encontrado consistência teórica de um autor no tratamento de determinadas questões justamente onde $o$ outro tinha debilidades flagrantes em sua teoria. Exemplo disso são: um elaborado conceito de sociedade em Habermas, que em Dussel se procura em vão; uma tematização das relações internacionais feita por Dussel, que em Habermas, com seu viés universalista, permanecem marginais.

Ponto de partida teórico desta comparação são elementos da teoria de Karl Mannheim sobre ideologia e utopia. Mas para preservar a capacidade explicativa da teoria de Mannheim no trato deste novo objeto foi necessário derivar, na primeira parte deste trabalho, cinco categorias que nos serviräo como indicadores: a avaliação da realidade, a utopia almejada, os portadores sociais desta utopia, as condições teóricas e práticas para a mudança social. Se bem que estas categorias apareçam em Mannheim, elas não têm lá o mesmo peso que lhes é atribuído aqui. Para apresentar a necessidade e a possibilidade desta derivação, Mannheim é tratado um pouco mais extensivamente.

Na segunda parte do trabalho as utopias da teoria da ação comunicativa e da filosofia da libertação são comparadas com base nestes indicadores. Na terceira parte é perseguida a pergunta se - e sob que condições - seria possível uma síntese de perspectivas, no sentido de Mannheim, entre estas duas teorias.

\section{1 - Para uma crítica das utopias}

A análise das obras de Jürgen Habermas e Enrique Dussel confronta as utopias subjacentes às suas teorias através de uma leitura imanente. ${ }^{1}$ Isto significa, de acordo com Karl Mannheim, uma leitura que reflete uma teoria, na medida do possível, dentro dos termos de seu próprio conteúdo doutrinal. ${ }^{2}$

Karl Mannheim parte da noção corrente segundo a qual "um estado de espírito é utópico quando está incongruente com o estado de realidade dentro do qual ocorre" (Mannheim, 1972, p. 216). Mas nem todo estado de espírito em incongruência com a realidade é utópico; utópicos são apenas aqueles que transcendem a

' De Habermas está em pauta sua Teoria da Ação Comunicativa (1988; 1989). Como complementação são oportunamente usados outros escritos. A leitura de Dussel tem como base livros do início dos anos 1970 (1982; 1986), nos quais ele apresenta seu programa de uma Filosofia da Libertação, e da segunda metade dos anos 1980 (1985; 1988; 1990), nos quais ele comenta a obra de Marx na perspectiva da filosofia da libertação.

Mannheim, 1982, especialmente parte 1, cap. 2 e 3. 
realidade e, se forem transformados em conduta coletiva, abalam parcial ou totalmente a ordem existente.

Enquanto transcendem a realidade, as idéias podem também ser ideologia. Tal é o caso quando as idéias, mesmo transcendendo a realidade, não são sistematicamente praticadas por seus portadores sociais. Com isso elas tornam-se socialmente impotentes. Estas idéias não levam a uma transformação global da sociedade; ao contrário, contribuem para manter o estado atual das coisas.

Utopias pressupõem sempre um portador social coletivo. Não obstante, Mannheim não exclui a possibilidade de que sua formulação inicial possa remontar a pessoas específicas. Ao contrário, para ele uma utopia com freqüência surgiu como quimera de um único indivíduo. Mas ela só poderá ser proveitosa para a vida coletiva do segmento social ascendente se, desde o princípio, estiver "em contato com algum problema importante e quando seus significados estão geneticamente enraizados nos objetivos coletivos" (Mannheim, 1972, p. 230).

Por conseguinte, segundo esta conceitualização, há duas características essenciais para que um conjunto de idéias ou mesmo uma teoria possa ser tido como utopia: que ele seja incongruente com a realidade histórica existente e que tenda a transformá-la em outra mais de acordo com as aspirações dos seus portadores sociais. Como bem anota Paul Ricoeur, utopias estão constantemente em processo de realização, enquanto as ideologias não enfrentam o problema de sua realização, pois são a justificação daquilo que já está realizado. Como estas duas teorias sociais são por seus formuladores tratadas como instrumento para a transformação da realidade social por eles analisada, elas aqui tomadas como uma tentativa de estabelecer uma consciência utópica.

Um postulado básico da sociologia do conhecimento elaborada por Mannheim é que existe uma estreita vinculação entre as teorias e a situação histórica e social de que emergem. Ideologias e utopias não apenas são sempre referidas a uma realidade, mas pertencem a um estrato social específico. Além disso, a utopia é o princípio arquitetônico que determina a seqüência, a ordem e a valoração das experiências singulares do estrato social. É ela quem dá forma e unidade à visão de mundo deste estrato; a avaliação do presente e do futuro é vista por esta ótica. A partir disso se pode entender que as utopias são mutuamente excludentes.

Mannheim desenvolve uma tipologia e apresenta quatro grandes utopias. A primeira é o quiliasma orgiástico dos anabatistas, seguida pela idéia liberal-humanitária, a idéia conservadora e culminando na utopia socialista-comunista. Sua ênfase está na mudança de mentalidade que ocorre entre as distintas correntes.

A primeira utopia é a que mais se afasta da realidade. Suas irrupções são imprevisiveis e indeterminadas quanto à sua direção. Nela há uma descontinuidade praticamente absoluta entre a realidade atual maligna e o futuro bom e perfeito. Já a idéia liberal-humanitária centra-se na força do pensamento e nos processos de formação e informação. Os processos sociais orientam-se pela projeção formal da perfeição no futuro infinito. Destarte não se rejeita de forma absoluta a realidade atual, apenas tenta-se ir remediando progressivamente suas imperfeições para aproximá-la do ideal. Ela segue o modelo do crescimento e maturação do indiví- 
duo, excluindo porém a velhice e a morte. Enquanto a primeira enfatiza o momento irruptivo como síntese do tempo e a segunda afirma o progresso, o terceiro tipo de utopia afirma a duração estável do tempo e exalta a tradição viva no espírito do povo. ${ }^{3}$ A quarta utopia, a socialista-comunista, sendo a última no movimento que vai do maior ao menor afastamento da realidade, alcança a mais próxima relação com a situação histórica e social. Esta relação é tão estreita que ela chega a uma espécie de assimilação das estruturas dadas. Esta utopia tende a uma espécie de síntese entre as anteriores, absorvendo-lhes diversos elementos. No tocante ao tempo, ela o utiliza para intervenções racionais no processo social, para finalmente alcançar seus objetivos estratégicos. Com isso ela se caracteriza como o oposto da primeira utopia.

A sequiência em que Mannheim apresenta as utopias revela sua percepção da História: uma aproximação gradual das utopias à realidade histórico-social e, portanto, sua decadência. As utopias socialista, conservadora e liberal são simplesmente um progressivo afastamento do quiliasma e uma aproximação aos eventos que transcorrem neste mundo (Mannheim, 1972, p. 280 ss.). Mas a utopia socialista venceu dois obstáculos claramente definidos desde o quiliasma: a indeterminação do sentido da História e a cegueira quanto às forças que a determinam.

Para fazer a comparação entre a teoria da ação comunicativa e a filosofia da libertação, no entanto, será relativizado o pressuposto mannheimiano de progressão ascendente na passagem de uma utopia a outra. De um lado, porque este autor pressupõe uma evolução social que não se aplica a todas as coletividades históricas, especialmente não para os países colonizados do Terceiro Mundo. Se bem que as utopias podem assimilar estruturas sociais e se adaptar parcialmente à realidade, em nosso entender não é possível deduzir disto que a utopia socialista tenha sido a última utopia. Por outro, porque isto nos obrigaria a tentar classificar estas teorias num dos quatro tipos de utopia descritos e valorizá-las segundo reflitam uma maior ou menor "evolução". Autores como Ricoeur, no entanto, já mostraram que o quadro traçado por Mannheim é incompleto e ignora algumas utopias importantes. O próprio Mannheim, aliás, não excluía de todo a possibilidade de que no futuro surjam outras utopias, quando novos estratos sociais poderiam trazer de volta os elementos utópicos de seus antecessores no embate por implantar novas formas de organização social (Mannheim 1972:280 ss.).

Por isso, conforme mencionado acima, em nosso estudo serão enfatizados cinco outros indicadores, já presentes em Mannheim, mas sem receber dele 0 destaque aqui concedido, a saber: a) a avaliação que cada autor faz da realidade atual, b) a nova realidade utópica almejada, $c$ ) os portadores sociais deste projeto de mudança social e a conceitualização d) das condições teóricas e e) das condições práticas para a mudança.

3 Chama a atenção que a utopia conservadora seja enfocada na obra de Mannheim após a liberal-humanitária, uma vez que historicamente este estrato social ascendeu antes ao poder. Pode-se suspeitar que isto seja uma influência hegeliana, uma vez que Hegel também trata os conservadores após os liberais; Mannheim tenta justificar esta seqüência com o argumento de que os conservadores apenas passaram a refletir sobre as bases de sua dominação quando passaram a ser fustigados por seus oponentes liberais. 
Quando Mannheim define utopia e a diferencia de ideologia, começa dizendo que "um estado de espírito é utópico quando está em incongruência com a realidade". ${ }^{4}$ Será utopia se, além da incongruência, sua implantação tenda a "pôr fim aos laços da ordem existente", o que a opõe à ideologia que são idéias "adequadas a este estágio da existência" e estão orgânica e harmoniosamente "integradas na visão de mundo característica do período". Com isso está implícita em Mannheim a necessidade de se fazer uma avaliação da realidade para poder contrastá-la com a utopia desejada. Esta é a razão pela qual começaremos a leitura de cada autor perguntando como ele avalia a realidade e qual a utopia que ele propõe como alternativa.

A simples descrição de um estado alternativo de coisas ou a presença de idéias desiderativas numa só pessoa, no entanto, não é ainda uma utopia. Para Mannheim, "somente depois que certos grupos incorporam as imagens desiderativas à sua conduta efetiva" é que elas se transformam de ideologia em utopia. Apreender quem é portador de uma utopia é fundamental para a sua compreensão: "a chave para a inteligibilidade das utopias consiste na situação estrutural do estrato social que, em um dado momento, as espose". A própria adaptação da utopia ao longo da História e das tentativas de sua efetivação está intimamente ligada à situação destes portadores na constelação geral da realidade. Por conseguinte, é importante perguntar quem são então os portadores da utopia na concepção de cada um dos autores que estudaremos.

Mannheim havia caracterizado as utopias como incongruentes com a realidade e tendentes a romper a ordem existente quando de sua implantação. Paul Ricoeur, nas suas reflexões sobre a obra de Mannheim (Ricoeur, 1986, p. 159 ss.; 269 ss.) critica a inconsistência destes critérios, especialmente 0 último, propondo em seu lugar a oposição à ordem existente. Ademais; ele enfatiza que o conflito entre ideologia e utopia, mais do que um problema teónico, é um conflito práticopolítico, cujo resultado não está predeterminado. Este tipo de disputa se dá tanto em torno da legitimidade de definições e interpretações como em torno de práticas políticas, pelo que será necessário analisar igualmente a forma como cada um dos autores em pauta conceitualiza as condições teóricas e práticas para a efetivação da mudança almejada. ${ }^{5}$

O gradativo declínio da utopia é visto por Mannheim como altamente problemático. Enquanto o fim das ideologias não afetaria mais que o respectivo estrato social que é seu portador, o fim das utopias "ocasiona um estado de coisas estático em que o próprio homem se transforma em coisa". Com isso a humanidade iria deparar-se "com o maior paradoxo imaginável, ou seja, o do homem que, tendo alcançado o mais alto grau de domínio racional da existência, se vê deixado sem nenhum ideal, tornando-se um produto de impulsos" (Mannheim, 1972, p. 285).

Mannheim, 1972,:cap. 4. As citações seguintes provêm do mesmo capitulo.

Neste contexto não podemos deixar de voltar a enfatizar que nosso estudo é teórico e tem como objeto teorias sobre a sociedade e sua transformação. Isso implica que os indicadores acima serão aplicados às produções dos dois autores, não sendo objeto aqui um estudo das realidades concretas a que eles se referem. 
Frente a este quadro, Mannheim vê como necessária uma solução qualitativamente nova. Se até aqui toda a utopia era fruto das necessidades de estratos sociais restritos, a atual convivência das diferentes possibilidades de visualizar 0 mundo coloca a necessidade de uma síntese destas perspectivas, de um quadro teónico que abranja todas elas. As certezas intelectuais anteriores eram parciais; agora que seus limites se tornaram tão evidentes, este seria um caminho para superá-los (Mannheim, 1972, p. 273 ss.). A possibilidade de serem estas sínteses elaboradas é mostrada pelo autor com base na existência de um pequeno estrato, o dos intelectuais, cuja visão de mundo e cujo conhecimento não está tão estreitamente vinculado aos seus estratos sociais de origem. Caso a vinculação fosse rigida, toda a teoria seguiria sendo necessariamente partidária; não o sendo, abrese a possibilidade de integração dos conhecimentos fragmentados numa visão mais abrangente. ${ }^{6}$ Como a realidade está em constante transformação, Mannheim vê como possíveis apenas sinteses relativas, reformuladas dinamicamente de tempos em tempos:

\begin{abstract}
"Uma verdadeira sintese não é a média aritmética de todas as diversas aspirações dos grupos existentes na sociedade. Se assim fosse, tenderia apenas a estabilizar o status quo em benefício dos que acabam de ascender ao poder e que desejam proteger seus ganhos contra os ataques tanto da 'direita' como da 'esquerda'. Pelo contrário, uma síntese válida deve se basear numa posição política que venha a constituir um desenvolvimento progressivo, no sentido de reter e utilizar boa parte das aquisições culturais e energias sociais acumuladas na época anterior. Ao mesmo tempo, a nova ordem deve permear os mais amplos setores da vida social, deve adquirir raizes naturais na sociedade, a fim de colocar em ação o seu poder de transformação. Esta poșição requer especial vigilância para com a realidade histórica do presente. 0 'aqui' espacial e 0 'agora' temporal de cada situação devem ser considerados no sentido histórico e social, e sempre lembrados a fim de, em cada caso, se determinar o que já não é necessário e o que ainda não é possível" (Mannheim, 1972, p. 179).
\end{abstract}

Tanto Habermas como Dussel incorporam aspirações, realizações parciais e desenvolvimentos teóricos de tendências distintas e por vezes contraditórias, buscando alcançar no conjunto um novo patamar para a discussão das questões que eles se propõem resolver. Isto nos permite a hipótese de que sua produção teórica seja uma tentativa de síntese de perspectivas, segundo a concepção de Mannheim. Em sendo uma síntese, não seriam capazes de uma aproximação recíproca, de um diálogo mutuamente enriquecedor? Conforme já foi explicitado acima, é esta questão central que nos move neste estudo comparativo.

A elaboração de sinteses tem, para Mannheim, inclusive importantes antecedentes históricos. Hegel, por exemplo, sintetizou o desenvolvimento alcançado até então pelas distintas tendências, concluindo assim toda uma época. Se, porém, esta síntese for tomada como absoluta, definitiva, poderá significar uma recaída na visão de mundo estática do intelectualismo. 


\section{2 - Habermas e Dussel: uma comparação}

\section{1 - Questões teónicas subjacentes às teorias}

Para facilitar o acompanhamento da comparação das duas teorias permitimonos uma breve recapitulação do problema teórico que cada autor se propõe a tratar, sem ter com isso qualquer pretensão de resumir suas teorias em tão pouco espaço. A recapitulação quer ter apenas um fim heurístico e situar para o leitor os indicadores usados no contexto da teoria a que são aplicados.

A obra de Habermas parte de uma preocupação que na Escola de Frankfurt ficou conhecida como o "paradoxo da racionalização". O paradoxo consiste em que a racionalização que possibilitaria aos homens o crescente domínio da Natureza e a libertação de dominações tradicionais trouxe consigo novas formas de dominação, alienação e de perda da liberdade.?

A racionalidade instrumental, que planeja, executa e avalia suas ações segundo os fins a serem alcançados, desenvolveu-se tanto no Ocidente que penetrou em âmbitos em que ela não é apropriada. Ela gera ações estratégicas e, por extensão, situações de comunicação passíveis de serem sistematicamente distorcidas, ao invés de impulsionar a busca da verdade e do consenso. Com isso ela perde sua intenção original que era liberar o homem face às contingências de sua natureza interna e externa.

Isto não é o fim lógico e necessário da razão, segundo Habermas, mas resultado de opções - equivocadas, é verdade - feitas ao longo do processo histórico. Não obstante, permanecem muitos resquícios de outras racionalidades, como a racionalidade comunicativa, a serem resgatadas. A teoria da ação comunicativa quer identificar onde o potencial destas racionalidades foi perdido e quais os caminhos para recuperá-lo, e assim contribuir para a emancipação plena da Humanidade.

Habermas não rejeita a racionalidade instrumental, mas quer vê-la restrita ao âmbito que, segundo sua visão de sociedade, lhe é próprio, o da reprodução material. Já nas esferas do valor, seguindo Weber, ele quer ver recuperada a racionalidade comunicativa e sua mediatização, a ação comunicativa. Com isso, pensa ele, não apenas estaria dada uma solução para o "paradoxo da racionalização", mas também estariam dadas as condições para reunir num novo conceito de sociedade dois paradigmas da discussão sociológica: o de ação social e o de sistema.

Mundo da vida é para Habermas o espaço em que se dá a integração social, coordenando as orientações da ação dos indivíduos em sociedade, enquanto no sistema - presente em seu conceito de sociedade como subsistemas economia e política - se dá a integração sistêmica, independente da ação dos indivíduos. A cada um corresponde um tipo de racionalização, comunicativa e sistêmica respectivamente, que Habermas entende como possibilidades complementares no mun-

Sobre a questão, cf. Habermas, 1989a, passim; McCarthy, 1985, cap. 1, 2, 5; Jay, 1976, passim. 
do moderno, que se requerem e condicionam entre si. A situação atual, então, não é um paradoxo, mas o resultado de um processo seletivo, de uma possibilidade entre outras na dinâmica do desenvolvimento da modernidade. Com isso está dada uma nova abordagem à necessidade do devir histórico na tradição hegeliana. Já não será mais o futuro produto da necessidade absoluta, do determinismo férreo, mas do dever ser (sollen), uma necessidade com liberdade, uma história com sentido.

A ação comunicativa, segunđo pretende o autor, ao mesmo tempo supera o paradoxo da racionalização e cria as condições de possibilidade de proposições prescritivas que, para Habermas, são fundamentalmente a descolonização do mundo da vida e a influência indireta deste sobre os subsistemas economia e política. Nisto consiste para Habermas a atual tarefa de emancipação humana.

Dussel coloca sinteticamente numa afirmação a questão central de sua teoria na forma de uma constatação e uma proposição, explicitando assim a sua avaliação da situação atual e a utopia buscada:

"O projeto vigente no mundo de hoje atribui aos nossos povos uma função bem pobre e sempre dependente na divisão internacional do trabalho, da cultura e da liberdade. $\mathrm{E}$ o que importa é chegar a participar livre, independente e justamente da civilização mundial que progride, da cultura humana que analogicamente se unifica em um plano mundial" (Dussel, 1986, p. 239).

A busca de uma participação livre, independente e justa nos diversos âmbitos da coletividade humana é do que se trata. A América Latina, como de resto também a África e a Ásia, é percebida como oprimida, dependente e empobrecida; ela é a exterioridade do sistema dominante. $\mathrm{O}$ homem da periferia é dependente em relação à dominação do centro norte-atlântico. Esta dependência é histórica e, por ser histórica, pode ser superada por um movimento de libertação que resgate 0 homem do seu ser-negado, do seu não ser. Para isto é preciso formular um sistema de interpretação latino-americano da América Latina e de sua libertação. Isto se fará, na concepção de Dussel, em termos teóricos com a superação do sistema de totalidade ontológica fechada em que se tornou a própria dialética. O novo sistema teórico será aberto, sem excluir ou negar o outro, o diferente, muito menos instrumentalizá-lo. Em termos práticos a libertação se dará pelo rompimento dos laços de dominação econômica e política dos pobres.

Esta libertação é muito mais que uma revolução, porque não é parcial nos seus interesses ou na sua abrangência, nem um processo que se esgota internamente ao sistema. Ela é práxis a partir do oprimido, do excluído, que é critério de sua verdade, para libertar a todos, inclusive o opressor. Não se esgotando internamente, também não poderão advir do sistema existente os conceitos que descrevem seus contornos. Eles se delineiam no e a partir do desenrolar do processo. Dussel expressa-o dizendo:

"O que a América Latina é vive-o o povo simples, dominado em sua exterioridade do sistema imperante. Mal podem dizer os filósofos o que é a América Latina liberta ou qual seja 
o conteúdo do projeto libertador latino-americano. O que o filósofo deve saber é como destruir os obstáculos que impedem a revẹlação do outro, do povo latino-americano que é pobre, mas que não é matéria inerte, nem telúrica posição da physis. A filosofia latinoamericana é o pensar que sabe escutar discipularmente a palavra analética, analógica do oprimido, que sabe comprometer-se com o movimento ou com a mobilização da libertação e, no próprio caminhar, vai pensando a palavra reveladora que interpela à justiça, isto é, vai acedendo à interpretação precisa de seu significado futuro" (Dussel, 1986, p 210 ss.).

Por isso lhe é tão fundamental escutar o outro, aquele que é exterioridade para o sistema atual. Enquanto a filosofia européia pode dizer que além do ser está o nada, a filosofia da libertação dirá que além do ser está o outro, o pobre, a quem lhe cabe ouvir, interpretar. Esta relação será pedagógica, onde se começa sendo discipulo atual do futuro discípulo, e é também analógica com relação à filosofia humana, ao colocar a outras filosofias no seu devido lugar.

\section{2 - $A$ avaliação da realidade atual}

A teoria da ação comunicativa e a filosofia da libertação, em sua avaliação da realidade atual, centram suas críticas em aspectos diferentes das sociedades modernas.

Habermas assume uma tradição da Escola de Frankfurt que durante décadas havia se perguntado como é possível relacionar de modo não contraditório a sociedade contemporânea com o esclarecimento e a emancipação humana. O caminho enveredado pela teoria crítica levou- à perda de confiança no potencial racional e emancipatório da modernidade. ${ }^{8}$ Uma reformulação radical no enfoque - mudança do paradigma da consciência para uma teoria da comunicação - é visto por Habermas como indispensável para que o programa da teoria crítica possa ser recuperado e o projeto da modernidade levado adiante. Com sua reconstrução da teoria social Habermas assumiu para si esta tarefa e fundamentou por que, em sua opinião, o projeto da modernidade deve ser resgatado, aprofundado e aperfeiçoado (Habermas, 1988, I, p. 505 ss.; 1989, p. 130 ss.).

Esta forma de modernidade, apologeticamente fundamentada por Habermas, é rejeitada por Dussel. Em seu lugar Dussel quer desenvolver uma filosofia da libertação que seja pós-moderna. ${ }^{9}$ Não se trata de uma rejeição da modernidade, como ocorreu posteriormente no pós-estruturalismo francês, mas de uma exigência de sua superação. Dussel exige que importantes aspectos da modernidade sejam reformulados, levando em conta especialmente a situação dos pobres. Em parte ele se refere a aspectos que por Habermas são considerados satisfatoriamente resolvidos e deixados de lado. Isto é particularmente válido para a organização da economia e da política.

" Habermas, 1989a, p 485; Jay, 1976, p. 292 ss.; McCarthy, 1985, passim. Siebeneichler (1990, p. 69 ss.) reconstrói as alternativas experimentadas por Habermas até chegar à teoria da ação comunicativa.

- A categoria filosofia pós-moderna é usada por Dussel desde o início dos anos 70 para descrever sua procura por uma filosofia que substitua na América Latina a filosofia moderna, opressora (Dussel, 1982, p. 9 ss; 1986, p. 196 ss.). Não tem, portanto, relação alguma com a posterior discussăo sobre modernidáde e pós-modernidade. 
Para Dussel, a modernidade européia sempre foi totalizante. Assumindo-se como a civilização, ela se impôs de forma dominadora aos que eram distintos. A história da conquista da América Latina é um exemplo para esta postura. Enquanto Habermas quer reconstruir o processo de racionalização da Europa em busca dos potenciais de racionalidade não instrumental que permitam superar as desvirtuações da modernidade, Dussel prioriza uma nova formulação da teoria, que parta do continente latino-americano e faça justiça a ele. Sua contribuição primeira quer ser a desmistificação da totalidade vigente e a criação de categorias que permitam pensar aquilo que está fora desta totalidade, a exterioridade (Dussel, 1982, p. 9 ss.; 1986, p. 19 ss.).

Em boa medida esta diferença deriva de distintas concepções antropológicas que cada autor pressupõe. Ao pressupor para sua utopia de sociedade uma intersubjetividade que se realiza nas ações comunicativas, com pretensões racionalmente diferenciadas de validade e dentro de uma situação ideal de fala, Habermas está antecipando a existência do homem universal, que atua de forma puramente racional. Diferenças culturais, visões de mundo não racionalizadas, sensibilidade e fantasia não são consideradas como características intrínsecas ao ser humano emancipado. Na reconstrução que Habermas faz do processo de racionalização ele evidencia o pressuposto que sociedades nas quais os homens não atuam de forma estritamente racional não atingiram ainda seu estágio ideal de maturação. Em Dussel, além da tematização do indivíduo há uma ênfase no comunitário, nas distinções regionais e culturais. O Outro é aceito como outro, sem a compulsão para padronizá-lo segundo critérios antropocêntricos. Dussel rejeita a concepção contida no eurocentrismo, segundo a qual os povos latino-americanos seriam meninos, que um dia se tornarão adultos; seres humanos pré-modernos, que um dia se modernizarão. Eles são, para Dussel, a outra face da modernidade européia, aqueles que pagam o preço da modernidade dos países do centro.

Mas ambos vêem como insatisfatória na realidade atual a geração daquilo que nas tradições hegeliana e marxista se denomina alienação. Este é o grande problema que cada um detecta naqueles aspectos concretos da realidade aos quais volta sua atenção. Habermas aponta para dois grandes problemas na realidade atual: a colonização do mundo da vida pelos imperativos dos sistemas e a crise do estado de bem-estar que foi construído no Ocidente após a Segunda Guerra Mundial (Habermas, 1988, II, p. 489 ss.; 1989, p. 413). Como causador da crise do estado de bem-estar, Habermas aponta a mescla entre 0 político e o econômico. Frente a racionalidades incompatíveis inerentes a cada um destes subsistemas, só são possíveis cooperações temporárias entre economia e política, para contornar ameaças comuns. Uma submissão prolongada da economia a mecanismos de controle político, conforme praticada no estado de bem-estar, é constantemente frustrada por novas crises. Assim também a atual crise foi precipitada pela desvirtuação do próprio mecanismo tido como solução contra crises: a tentativa de controlar o subsistema economia através do poder, o mecanismo que rege o subsistema político. Também o mundo da vida está desprotegido frente aos ataques da racionalidade instrumental, que orienta predominantemente as ações nos subsistemas economia e política: Ao invés de cooperações ou mesclas dos diferentes 
âmbitos como prevenção ou superação de crises, Habermas divisa como eficaz apenas a completa distinção entre política, economia e mundo da vida.

Dussel, por seu turno, percebe a realidade atual a partir da América Latina e assume da discussão sobre a dependência categorias como dependência e centroperiferia. Segundo ele, a realidade atual do continente está caracterizada pela alienação. O sistema dominante nega a exterioridade do Outro e o instrumentali$\mathrm{za}^{10}{ }^{10}$ Nas relações entre capital e trabalho, a alienação se expressa como negação da humanidade do homem; nas relações internacionais ela assume a forma de dependência. Tanto a alienação como a dependência são expressões da dominação de sistemas totalizantes. Àqueles que não participam deste sistema é negada a existência como absoluta exterioridade.

$\mathrm{Na}$ filosofia tradicional, segundo Dussel, esta realidade de dominação se manifesta na pretensa centralidade do sujeito cognoscente europeu, que exclui e nega os demais em seu ser-diferente, bem como na pretensa neutralidade da filosofia clássica, que oculta seus compromissos ideológicos. Dussel vê uma das fontes destas distorções e da dominação que lhes é correlata no uso da dialética nos países do centro, especialmente quando se nega a existência a tudo o que por ela não puder ser abarcado.

No seu comentário a Marx, a economia é um dos âmbitos que Dussel tematiza e critica. $\mathrm{O}$ atual modo de produzir mercadorias, segundo ele, aliena o trabalho. Não que não possa haver trabalho remunerado; a questão é que o atual sistema subjuga o homem todo e o anula em seu ser-homem, enfrentando-o apenas como a mercadoria força de trabalho. Em oposição a esta realidade é então almejado um reino da liberdade, onde cada um poderá usufruir do fruto do trabalho segundo as necessidades, e do lazer segundo os desejos. Para chegar a ele, o autor privilegia o âmbito da política como o campo de ações libertadoras (Dussel, 1988, p. 37 ss.).

Em comum Habermas e Dussel têm, portanto, uma avaliação negativa da realidade. Ambos estão trabalhando em torno da questão da alienação. Mas ao encetar sua crítica principalmente ao relacionamento entre âmbitos parciais do sistema, Habermas sinaliza uma avaliação em princípio positiva deste sistema e a intenção de preservá-lo. A crítica de Dussel, ao contrário, tem a pretensão de ser muito mais abrangente e se dirige contra o todo do sistema. Em resumo, observando-se a teoria da ação comunicativa e a filosofia da libertação sob o aspecto da avaliação da realidade atual, tem-se a impressão de que Habermas quer retificar algumas partes do sistema atual, sem buscar outro, radicalmente alternativo, enquanto Dussel quer desmontar todo o sistema capitalista, controlado a partir dos países industrializados, e reter para a nova ordem social apenas algumas de suas conquistas.

10

0 que Dussel tem em mente com isso fica claro quando defenda que o pobre antes de começar a trabalhar como assalariado é exterioridade para o sistema capitalista de exploração do trabalho. Se o pobre vende sua força de trabalho, ele não só é alienado (conforme descrito por Marx), mas também integrado ao sistema (capitalista); com isso ele perde sua independência frente a este sistema e sacrifica sua humanidade em favor dos objetivos do sistema. (Dussel, 1985, p. 350 ss., 371 ss.; 1988, p. 312 ss.). 


\section{3 - A utopia pressuposta por Habermas e Dussel}

A avaliação crítica da realidade não pode ser dissociada da realidade utópica que cada autor tem como pano de fundo em suas análises. Mesmo sendo Habermas muito cuidadoso no uso do termo utopia, ele trabalha claramente em função de um projeto utópico que aparece em suas obras basicamente sob dois aspectos. De um lado, quando teoriza a respeito da ação, num nível altamente abstrato, ele faz determinadas antecipações para que a ação comunicativa seja possível. A situação ideal de fala é a mais abrangente destas antecipações. Trata-se da antecipação de uma situação em que a comunicação ocorre livremente, sem coações internas ao processo e sem ingerência de contingências externas (Habermas, 1989 a, p. 489). Por outro, quando tem em vista o contexto mais amplo e sua dinâmica política, Habermas defende um processo radicalmente democrático de formação das vontades, baseado na solidariedade, e o exerćício do poder popular através deste mecanismo (Habermas, 1990). Com isso, para Habermas estaria assegurado o bom viver e uma relação harmônica entre o mundo da vida e os subsistemas economia e política, com suas racionalidades específicas (Habermas, 1989, p. 415 ss.; 1987, p. 113 ss.).

Ao definir como filosofia da libertação o seu empreendimento teórico, Dussel coloca em relevo desde logo seu projeto desiderativo: a libertação. Em vinculação com Marx, uma das designações usadas por Dussel para definir este objetivo é a expressão reino da liberdade (Dussel, 1985, p. 356 ss.). Este reino da liberdade se caracterizaria pelo pleno desenvolvimento do indivíduo e de sua liberdade, pelo livre intercâmbio dos frutos do trabalho entre os membros da comunidade e pela colocação do desenvolvimento tecnológico a serviço do bem de todos os membros da coletividade. Para que este reino possa ser estabelecido, é necessária a segunda emancipação em dois aspectos: libertação da dependência das nações latinoamericanas frente ao domínio neocolonial do capital desenvolvido e libertação do povo oprimido no interior da nação (Dussel, 1986, p. 240 ss.). Influenciado pela concepção semita do êxodo do Egito, Dussel coloca a realização desta nova sociedade como a tomada de posse da terra prometida, na qual o respeito à alteridade do outro será o critério fundamental com base no qual será determinado quais aspectos do capitalismo serão resgatados e desenvolvidos.

Percebe-se também aqui uma diferença na concepção antropológica de Habermas e Dussel. Ao ver no homem fundamentalmente sua condição de ser racional com orientação universal, Habermas se distancia de Dussel, que vê o ser humano como homem ou mulher, mestiço ou índio, como corpo, alma e espírito, produtor de bens para a satisfação de necessidades nos mais distintos âmbitos de sua vivência. Não obstante, é importante ressaltar a semelhança dos autores quanto às suas expectativas teleológicas, porque são fundamentais na formulação dos critérios que subjazem à constituição de suas teorias.

Os dois autores preconizam enfaticamente como projeto utópico a constituição de uma sociedade onde os relacionamentos entre os seres humanos sejam livres e pautados pelo respeito recíproco. Em conjunto as pessoas definirão como será estruturada sua sociedade. Isso leva os autores a uma valorização positiva da democracia como processo de formação da vontade dentro da sociedade. Haber- 
mas, é verdade, enfatiza mais a parte formal do processo democrático e se recusa a vir ao encontro de seus críticos quando pedem dele uma argumentação baseada em conteúdos (Habermas, 1989a, p. 477 ss.). enquanto Dussel tenta justamente colocar para a democracia determinados conteúdos mínimos que assegurariam 0 bem-comum. No limite, no entanto, ambos colocam como objetivo o fim do sistema capitalista e a construção de uma sociedade amplamente pluralista. Determinante para ambos projetos de sociedade é uma exigência fundamental: o fim de toda e qualquer forma de instrumentalização ou dominação do homem pelo homem, a garantia da liberdade de cada um como antídoto à alienação.

\section{4 - Condições teónicas da utopia}

Observando a forma como construiu a teoria da ação comunicativa, percebese que Habermas desenvolve o conceito de racionalidade comunicativa como a base de toda sua teoria. Para Habermas, ela a rigor já esteve presente na obra de outros teóricos sociais, mas não recebeu um lugar central (Habermas, 1988, I, p. 25 ss.). Racionalidade comunicativa é uma postura frente ao outro, ao interlocutor, que prioriza 0 entendimento. As ações que seguem esta racionalidade são ações comunicativas e seu lugar é o âmbito da reprodução cultural, que Habermas denomina mundo da vida.

Há, no entanto, outros âmbitos nos quais as ações seguem outra racionalidade. Para Habermas, dois têm especial importância: os subsistemas economia e política. Para relacionar o mundo da vida com estes dois subsistemas, ele desenvolve um novo conceito de sociedade, compreendendo dois patamares: um patamar é formado pelos subsistemas economia e política e nele ocorre a reprodução material da sociedade; o outro patamar abrange o mundo da vida, no qual ocorre a reprodução cultural. Entre eles há mecanismos de intercâmbio, sem que sejam desejáveis interferências diretas de um âmbito em outro. Com este conceito de sociedade Habermas quer abranger sinteticamente os conceitos de sociedade da teoria sistêmica e das teorias da ação social (Habermas, 1988, II, p. 447 ss.; 1989a, p. 571 ss.).

A categoria fundamental desenvolvida por Dussel é a da exterioridade. Ela descreve a relação dos pobres e oprimidos com o sistema dominante: não estar inserido no sistema, estar fora dele (Dussel, 1982, p. 45 ss.; 1986, p. 231 ss.). Com esta categoria Dussel não apenas quer reformular o método do fazer filosófico, mas também apontar para as condições necessárias para uma reformulação da organização social, política, econômica e ética da sociedade. No âmbito metodológico, especialmente nos escritos dos anos 70, Dussel quer substituir a dialética pela analética (Dussel, 1986, p. 196 ss.). Não se trata de um método novo, mas de uma nova postura frente à dialética, fazendo dela um método no qual se parte do Outro como ser humano livre, do diálogo com o outro para servi-lo criativamente. Com isso pretende levar os filósofos a abandonarem o solipsismo, pelo qual historicamente fizeram da dialética um movimento de dominação. Também as atuais relações de dominação devem ser desfetichizadas desta forma (Dussel, 1986, p. 189 ss.). 
Os dois autores têm em comum uma postura bastante eclética frente às diversas tradições teóricas das quais eles fazem uso. Eles buscam resgatar delas aquelas categorias que lhes pareçam positivas e úteis, para integrá-las numa nova unidade teórica. Mannheim denominou esta postura síntese de perspectiva. Mas para Mannheim, a síntese não se refere apenas ao aproveitamento teórico de elementos esparsos, mas descreve todo o conjunto do projeto utópico que emerge deste processo.

De certa forma aqui se repete o fenômeno já visto ao tratar a questão da utopia: enquanto Habermas desenvolve uma teoria formal dos processos sociais, Dussel coloca um critério de conteúdo como base da ética. Enquanto Habermas tematiza os processos formais que devem levar ao consenso sobre os conteúdos, Dussel parte de um suposto consenso sobre este conteúdo, para que os partícipes encontrem as formas concretas de organização social que queiram construir. Mas é importante ressaltar que o respeito à exterioridade do Outro em Dussel e a busca do consenso livre de coerção em Habermas como pressupostos indispensáveis na construção de uma sociedade livre de dominaçäo do homem pelo homem e de imperativos sistêmicos, na prática ocupam o lugar de um núcleo gerador de uma ética. Ademais, como condições teóricas, estão muito próximas uma da outra. Como também os objetivos utópicos nas duas teorias se aproximam, esta questão teórica poderia ser um ponto de partida para uma eventual síntese entre estas duas perspectivas.

\section{5 - Condições práticas da utopia}

A prática que Habermas entende como necessária para a transformação da realidade atual de acordo com seu projeto utópico é por ele descrita como descolonização e proteção do mundo da vida frente à racionalidade instrumental, predominante nos subsistemas economia e política. Para que o mundo da vida possa permanecer livre das interferências indesejadas dos subsistemas, ele vê como necessária uma nova distribuição dos mecanismos reguladores predominantes em cada âmbito: o dinheiro na economia, o poder na política e a solidariedade no mundo da vida (Habermas, 1989, p. 415 ss.). O necessário incremento da solidariedade se dá principalmente nos movimentos sociais (Habermas, 1990). Outro fator importante para proteger o mundo da vida é o desenvolvimento de processos radicalmente democráticos de formação pública da opinião. Com isso Habermas espera até uma certa inversão da situação atual: que o mundo da vida possa influenciar indiretamente os subsistemas através dos estímulos desta opinião pública (Habermas, 1989, p. 421 ss.).

Para Dussel, a superação da realidade atual acontece através da práxis libertadora dos pobres. Inspirada na experiência do êxodo dos hebreus (pobres) do Egito, esta práxis destrói as amarras da dominação e vai em busca da terra prometida. Não se trata de sair geograficamente, como os hebreus, que migraram do Egito para a Palestina, mas de libertar-se geopoliticamente de uma situação de opressão e a construção de uma sociedade nova, política, econômica e culturalmente pluralista. Núcleo central desta transformação é a participação dos pobres e 
oprimidos, que estão excluídos dos benefícios do sistema dominante atual, na libertação e na construção de uma sociedade nova, livre. Estas condições práticas da utopia estão formuladas em boa medida em termos extraídos da práxis revolucionária clássica do marxismo, porém com ênfase na necessidade de uma pluralidade cultural numa composição mais abrangente dos portadores sociais da nova utopia.

Tanto Habermas como Dussel colocam como indispensável uma práxis renovadora que parte do contexto historicamente dado, analisa-o criticamente e nele intervém, para transformá-lo. A diferença na conceitualização desta práxis provém principalmente da abrangência da renovação esperada. Enquanto Habermas assume a economia e a política como sistemas auto-regulados, com livre ação em seus respectivos âmbitos, propondo uma práxis que a rigor transforma apenas as relações no interior do mundo da vida e deste com os subsistemas economia e política (Habermas, 1989, p. 423), Dussel vê como indispensável uma transformação abrangente, tanto no interior das sociedades nacionais como das relações internacionais. Se, porém, ele quer preservar e inclusive impulsionar o que há de humano no capitalismo, como a tecnologia e a democracia, é possível perguntar se a universalização da proposta de democracia radical feita por Habermas com vistas a mudanças na forma de fazer política, em especial sua adaptação também à economia, não se aproximaria de uma práxis libertadora no sentido dado por Dussel. Uma sociedade na qual, segundo a concepção de Habermas, o mundo da vida está descolonizado e protegido, e influi através de estímulos indiretos sobre os subsistemas economia e política, preenche no essencial as condições da libertação conforme exigida por Dussel.

\section{6 - Os portadores da utopia}

No tocante à concepção sobre os portadores das respectivas utopias e sua constituição como agentes da transformação social, Habermas e Dussel enfatizam aspectos diferentes em suas teorias. Dussel, dentro da tradição da crítica da ideologia, atribui ao filósofo e a outros intelectuais uma tarefa esclarecedora fundamental. São eles que ajudam o povo a ver mais longe e a perceber as ciladas da ideologia dominante; são eles que acolhem as aspirações deste povo e as devolvem teoricamente refletidas. Como para Habermas é impossível que a sociedade atue sobre si mesma como sujeito coletivo, ele atribui esta tarefa aos diversos processos de formação pública da opinião. Sua ênfase não está em objetivos ou no engajamento em favor de valores determinados, nem na determinação dos portadores da transformação social, mas nos processos (Habermas, 1989, p. 415 ss.).

Possivelmente esteja por trás desta divergência também uma confiança muito maior de Habermas com relação às possibilidades de entendimento em situações conflitivas. Habermas tem sido acusado de teórico do consenso no sentido de nâo perceber 0 alcance dos muitos processos conflitivos que há na sociedade. Esta acusação, em nossa opinião, não procede. Toda sua teoria do discurso é justamente em função do dissenso não só como possibilidade, mas como regra na sociedade. Só que ao circunscrever este dissenso ao mundo da vida, ele ao mesmo tempo 
delimita o raio das possíveis ações sociais transformadoras. A partir de seu conceito de sociedade, Habermas somente pode derivar uma influência indireta sobre 0 que se passa no interior dos subsistemas economia e política.

A teoria de Dussel está perpassada pela tese de uma sociedade repartida basicamente em dois grupos, na qual se luta pela manutenção, respectivamente pela superação da dominação. Por isso ele se mostra cético quanto à possibilidade de construir relações de consenso com argumentos de solidariedade, para exercer desta forma uma influência decisiva na política e na economia. Zimmermann (1987, p. 27 ss.) mostra como a experiência pessoal de ser perseguido e forçado ao exílio pelas camadas dominantes, que buscam defender seus privilégios com todos os meios, exerceu uma influência forte sobre Dussel e o fez perder a confiança na possibilidade de transformar a realidade latino-americana na base do consenso.

Por outro lado, é possível perceber convergências nada desprezíveis entre os dois autores na forma como concebem os portadores sociais da utopia. Na teoria da ação comunicativa não há lugar para tematizar a formação de um grande sujeito coletivo que realizaria a transformação. Em lugar de um sujeito Habermas concebe processos de formação pública da opinião, cuja unidade básica é a ação comunicativa entre, no mínimo, dois partícipes. Não obstante, o adensamento destes processos pode condensar-se como uma intersubjetividade de ordem superior, dando origem a movimentos sociais. São estes que levantarão as barreiras de proteção, com as quais o mundo da vida deve ser protegido frente aos imperativos dos subsistemas.

Para Dussel, a libertação pressupõe dois momentos: a destruição do sistema de dominação e a construção de uma ordem nova. Em ambos momentos devem atuar conjuntamente os intelectuais e o restante do povo. Povo para Dussel é uma coletividade organizada, com memória histórica, identidade, estruturas próprias, e não simplesmente uma massa informe. Diferente da tradição marxista clássica, este sujeito histórico não é uma classe social em particular, mas potencialmente 0 conjunto de todos os oprimidos e excluídos do sistema: trabalhadores da ativa, desempregados, minorias, etc.

No nível de abstração com que estamos trabalhando em nossa comparação, percebe- se uma proximidade entre Habermas e Dussel: os portadores sociais do projeto utópico tendem a ser coletividades organizadas, cujo recorte não é determinado por condições estruturais, como a classe social, mas por sua inserção prática no processo social. Aquilo que Habermas denomina intersubjetividades superiores aproxima-se muito e equivale dinamicamente ao que Dussel, em seu contexto, denomina povo. Isso obviamente não exclui outras questões, como a das relações de poder destes portadores sociais da transformação frente aos mantenedores do status quo, ou mesmo das estratégias concretas de enfrentamento e superação da realidade. Ambos prevêem que estes portadores da utopia transformarão a realidade atual. Para Dussel, a nova realidade será um socialismo. Uma observação acurada mostra que as suas concretizações em Habermas apontam nesta mesma direção (Habermas, 1987a, passim). 


\section{3 - Para uma sintese de perspectivas}

Com base na comparação feita entre as teorias de Habermas e Dussel sustentamos que, a despeito de diferenças contextualmente condicionadas, a teoria da ação comunicativa e a filosofia da libertação vinculam-se à mudança social de tal maneira que é possível e até razoável aspirar a uma síntese de perspectivas entre elas, no sentido proposto por Mannheim. A forma como em cada teoria se descreve a utopia é diferente, em conformidade com seu contexto de origem e o universo ao qual se referem. Ambas, no entanto, partilham uma razão utópica que, no horizonte, coloca uma sociedade solidária e participativa, "socialista", como alternativa para superar a realidade atual.

Uma revisão da produção teórica anterior e uma apropriação seletiva de distintas tradições caracteriza ambos autores. Ambos reivindicam para si o reconhecimento de que ainda permanecem no espectro da tradição marxista, mas querem superar deficiências com ela herdadas. Dussel toma como alvo inicial de sua crítica a dialética e propõe sua substituição por uma dialética verdadeira, que não anule 0 outro em sua exterioridade. Sua recente releitura de Marx foi de grande importância, pois nela encontrou uma base teórica para a categoria exterioridade, considerada mais sólida do que antes, quando se apoiava em Levinas e Heidegger. Com esta releitura Dussel pretende dar continuidade à obra de Marx, assimilando categorias de Marx e da tradição marxista e reelaborando-as de tal maneira que sirvam para refletir a realidade latino-americana. Destaque neste sentido é sua reformulação da questão da dependência.

Habermas, por seu turno, resgata a racionalidade comunicativa que, segundo ele, foi perdida na tradição, para construir com base nela uma nova teoria da ação. Sem dúvida este é o ponto forte de sua teoria que, de forma coerente, ele denominou teoria da ação çomunicativa. Com a inserção da teoria dos sistemas num novo conceito de sociedade, ele sugere uma nova versão para a mediação entre os âmbitos micro e macro, entre ação social e sistema. Falta na teoria da ação comunicativa a tematização das relações internacionais, entre capitalismo central e 0 capitalismo dependente, decisiva para a América Latina.

$\mathrm{O}$ que Dussel nã̃o desenvolveu foi uma teoria da ação social das relações microssociais. Ele critica a perspectiva totalizante das teorias européias porque elas não conseguem admitir o Outro senão como objeto ou como ainda-não-europeu. Frente a isto, sua proposição da categoria exterioridade e as concretizações históricas que ela pode assumir são sem dúvida um passo correto na direção de uma melhor compreensão da realidade. O necessário respeito ao ser distinto, à autonomia e à não-redutibilidade daqueles que não são como eu/nós são as exigências éticas levantadas por esta categoria e simultaneamente a base de toda ética em Dussel. A aceitação do Outro como Outro é para ele uma condição indispensável para que relações eqüitativas, não distorcidas, sejam possíveis no interior de uma sociedade, mas também entre sociedades distintas. Com isso Dussel generaliza uma exigência que Habermas faz para o mundo da vida, mas não estende à política e à economia. 
Mas o respeito ao Outro não explica como ocorrem os processos sociais nem como é possível a coesão social, para citar apenas duas questões fundamentais nas ciências sociais. Como nesta área está justamente um ponto forte de Habermas, é possível perguntar se não seria possivel reformular a ética dusseliana em termos da teoria da ação comunicativa. Para tanto seria necessária uma teoria para a superação dos conflitos naqueles âmbitos que Habermas relega à autoregulação: na economia e na política.

A falta de uma teoria social parece estar relacionada com um certo simplismo em Dussel. Ao ler seus escritos fica-se com a impressão de que ele considera os habitantes dos países centrais como partícipes do sistema, enquanto os habitantes dos países periféricos, exceto a elite dominante, sejam exterioridade para o sistema. O simples fato de ser exterioridade para um sistema dado, no entanto, não é suficiente para constituir uma unidade nova, como, por exemplo, o povo. A referência negativa com relação a um sistema, dada pela categoria exterioridade, não tem em si nenhuma implicação afirmativa com relação à constituição de uma práxis alternativa. Marx já havia percebido isto ao distinguir entre classe em si e classe para si. Se Dussel estiver - como parece - pressupondo este tornar-se povo para si da tradição marxista, comete o equívoco de não levar em consideração justamente os problemas para a constituição de um sujeito histórico atuante que experiências históricas, como o movimento operário, revelaram. A constituição de um portador coletivo de uma utopia requer muito mais que a descrição de quem deveria fazer parte dele. Talvez fosse possível adaptar aqui o esquema formal de Habermas acerca da formação pública da opinião (Habermas, 1990), mas levando em consideração o contexto latino-americano.

Aparentemente a necessidade e possibilidade desta complementação deveria ser percebida por Dussel. A América Latina dispõe de uma longa tradição marxista contextualizada, na qual estas questōes foram amplamente tratadas. Também os novos movimentos sociais, que nas últimas décadas se espalharam por praticamente toda a América Latina, em vários países se tornaram uma considerável força política, poderiam desempenhar um papel central no processo de libertação almejado pela filosofia da libertação. Mas Dussel desconsidera tanto esta tradição marxista como os novos movimentos sociais.

Nos escritos de Dussel não está tematizada nem é levada em consideração a diferenciação de esferas de valor com lógicas próprias e autonomia relativa, como ela foi acolhida na tradição weberiana (Habermas, 1988, I e II, passim). Não obstante as reiteradas tentativas de se dominar com a lógica de uma esfera também em outras, uma diferenciação e, por conseguinte, uma relativa autonomia da cultura, da política e da economia nas sociedades ocidentalizadas é inegável. Ao não acolher esta diferenciação, a descrição dos problemas do sistema atual de Dussel é insuficientemente complexa. Pelo menos no que tange ao mundo da vida, Habermas tem sabido incorporar muito bem estas diferenciações e complexificou sua teoria social.

Ao fazer a diferenciação, a nosso ver, Habermas comete um equívoco: ele considera como dada a autonomia dos subsistemas economia e política. Ele tomaas praticamente como máquinas não triviais, que têm um input e um output, sem 
que o mundo da vida tivesse acesso ou influência direta no processamento interno. Com isso ele desconhece que tanto a política como a economia são emaranhados de relações sociais, nas quais as pessoas estão tão envolvidas como com seu mundo da vida.

Habermas retoma a questão da relação entre o mundo da interação e o mundo do trabalho, que vem de Hegel e Marx. Hegel prioriza o mundo da interação de forma tão absoluta (incluindo nele o Estado), que o mundo do trabalho ficou virtualmente ausente de sua reflexão. Marx inverteu este modelo: concentrou-se tanto no mundo do trabalho que deixou para o mundo da interação apenas um lugar reflexo. Habermas resgata estes dois aspectos, incorporando-os no seu conceito de sociedade. Contudo, ao tomar os dois subsistemas como dados, ele os fetichiza. Isto tem como conseqüência a consagração do status quo nestas duas esferas. As tradições marxista e da teoria crítica no entanto mostraram reiteradamente como são distorcidos os processos nestes sistemas.

Para que a teoria da ação comunicativa tenha um poder explicativo na América Latina, faz-se necessário revisar o que foi relegado aos dois subsistemas. Porquanto toda a organização da economia e da política está permeada de relações interpessoais, haveria que estender a elas uma racionalidade que exclua toda e qualquer instrumentalização do homem pelo homem. Ações racionais com respeito a fins, nas quais um sujeito domina um objeto, eventualmente poderiam ser legitimadas como relação com a Natureza, mas jamais degradando seres humanos à condição de objeto. Contra esta degradação do ser humano, indiretamente aceita por Habermas, a categoria de exterioridade, de Dussel, poderia ser de grande proveito.

Outra deficiência, que aparentemente decorre desta aceitação do status quo nestes subsistemas, é a já mencionada não-tematização dos mecanismos de dependência internacional. A teoria da ação comunicativa não consegue refletir as relações políticas e econômicas que ultrapassam as fronteiras do país. Falta-lhe a complexidade conceitual para perceber que em termos de relações internacionais não há relações puramente econômicas ou puramente políticas. Assim, no fundo, a teoria de Habermas, a despeito de sua pretensão universalista, fica limitada às microações, enquanto Dussel divisou a macrotransformação da sociedade, sem contudo tematizar seus mecanismos e possibilidades. Estas constatações podem ser um bom estímulo com vistas a uma possível complementaridade entre estas teorias.

Para finalizar nossa análise comparativa queremos listar ainda alguns pontos em que, segundo nos parece, a teoria da ação comunicativa e a filosofia da libertação poderiam ir além das complementações sugeridas acima, para superarem-se mediante uma síntese global de perspectivas.

1. As condições de possibilidade do entendimento precisariam ser universalizadas radicalmente. Isto requer mudanças profundas na economia e na política, mas também no mundo da vida. Estas mudanças requerem que se tematize justamente aquilo que Habermas pressupõe como dado em sua teoria da ação comunicativa: que o outro seja efetivamente aceito assim como ele é, sem forçar seu enquadramento em categorias universalistas. 
2. Por mais que Habermas se oponha, isto não pode acontecer sem o estabelecimento de conteúdos, pelos quais esta estrutura formal de ação se orienta. 0 respeito absoluto ao Outro enquanto exterioridade do mundo da vida pode ser o topo desta arquitetura, mas são necessários ainda outros elementos. Os partícipes das ações orientadas ao entendimento não são apenas caracterizados como seres racionais, mas são pessoas humanas que têm corpo e alma e, portanto, necessidades materiais, espirituais, religiosas, afetivas etc.

3. A passagem do eu solipsista ao nós da comunidade de comunicação é sem dúvida um passo importante. Mas é preciso perguntar claramente quem está incluído e quem permanece excluído do horizonte do possível consenso. Num contexto onde a conflitividade for menor - isto é, onde as distâncias entre os partícipes da comunidade da comunicação sejam pequenas e o dissenso seja em torno de questões menos essenciais - 0 consenso talvez seja mais fácil e uma eventual persistência do dissenso não tenha conseqüências vitais. Aclaradas as condições de possibilidade para o consenso neste nível, no entanto, é preciso perguntar-se pelos excluídos desta possibilidade, pelos "outros". Vejamos isto em dois níveis: nas relações econômicas e nas relações internacionais.

4. Habermas, em sua teoria da ação comunicativa, continua partindo do pressuposto de que nos países do capitalismo avançado a emancipação não pode mais ser expressa em termos econômicos, porque a alienação já perdeu sua face econômica e a miséria não é um fator significativo a considerar. ${ }^{11}$ Isto parece mostrar que ele não compreendeu ou não aceita uma questão que já em Marx era fundamental: que as relações de trabalho na sociedade capitalista são relações sociais, e não meramente instrumentais. Com sua exigência de uma democracia radical Habermas já indicou para o âmbito da política como a mudança social pode ser tematizada pela teoria da ação comunicativa no interior do subsistema.

5. A teoria da ação comunicativa deixa em aberto uma questão fundamental: o conflito entre ricos e pobres. Há anos multiplicam-se análises que tentam mostrar que a universalização dos padrōes de vida dos países ricos é inviável. Se, porém, os pobres dos países dependentes exigirem uma partilha universal da riqueza, haverá ainda possibilidade de estabelecer um consenso num nível universal? Dito de outra forma: como se bloqueia atualmente a possibilidade de os pobres ampliarem sua participação no consumo e como poderá ser alcançado que eles obtenham dos frutos do seu trabalho pelo menos o necessário para si e seus familiares? Na História há muitos exemplos que mostram como a simples vontade de independência - para nem falar da participação justa e eqüitativa nos benefícios trazidos pelo desenvolvimento - de alguns países foi respondida com agressões, guerras e massacres pelos dominadores. Mas é precisamente sobre os pobres destes países que pesa a conta da modernidade (Dussel, 1990, p. 331). O que mais se necessita, pelo menos na perspectiva latino-americana, é uma teoria sobre como romper o consenso tácito dos ricos contra os pobres, para que estes possam viver.

"Esta suposiçăo Habermas defende no minimo desde 1968, quando publicou Teoria e práxis. 
6. Isto não significa que a teoria da ação comunicativa não possa ter utilidade para a América Latina. Trata-se apenas de reconhecer suas limitações. Sua utilidade atual está em colocar à disposição ínstrumentos para questionar a legitimidade de relações sociais dentro de âmbitos parciais de uma sociedade dada. Como reflexão mais ampla, pode-se dizer que a teoria da ação comunicativa será necessária como prevenção contra deteriorações quando a sociedade utópica almejada por Dussel tiver sido realizada.

7. Com a universalização das condições pressupostas por Habermas para o consenso nos termos acima mencionados, a dicotomização entre os paradigmas do sujeito e da comunicação ficaria destituída de sentido. Desde o momento em que ninguém mais for tomado como objeto, problemas relacionados com o solipsismo do sujeito desaparecem.

\section{Referências bibliográficas}

AZEVEDO, Edmilson Alves de (1990): Dialética e razão em Jürgen Habermas: da filosofia negativa da história à ética do discurso. Dissertação de mestrado. Porto Alegre: Universidade Federal do Rio Grande do Sul.

BORGES, Bento I. (1988): Fundamentação discursiva da teoria crítica de Habermas. Dissertação de mestrado. Porto Alegre: Universidade Federal do Rio Grande do Sul.

BOUFLEUER, José Pedro (1991): Pedagogia latino-americana: Freire e Dussel. Ijuí: Livraria Unijuí.

DUSSEL, Enrique (s. d. (1982)): Filosofia da libertação na América Latina. 2. ed. São Paulo: Loyola.

. (1985): La producción teórica de Marx: un comentario a los Grundrisse. México: Siglo 21.

. (1986): Método para uma filosofia da libertação. São Paulo: Loyola.

(1988): Hacia un Marx desconocido: Un comentario de los manuscritos del 61-63. México:

Siglo 21 .

. (1990): El último Marx (1863-1882) y la liberación latinoamericana. México: Siglo 21.

GROLLI, Dorilda (1988): O projeto alterativo das CEBs. Uma abordagem filosófica a partir de Enrique

Dussel. Tese de mestrado. Porto Alegre: PUC.

GUIDDENS et. al., Antony (1988): Habermas y la modernidad. Madrid: Cátedra.

HABERMAS, Jürgen (1987): "A nova intransparência: a crise do estado de bem-estar social e o esgotamento das energias utópicas". In: Novos Estudos, São Paulo, n. 18, p. 103-14, set.

. (1987a): "Um perfil filosófico-político: entrevista com Habermas". In: Novos Estudos, São

Paulo, n. 18, p. 77-102, set.

(1988 I e II): Theorie des komminikativen Handelns. Frankfurt: Suhrkamp. 2 v.

(1989): Der philosophische Diskurs der Moderne. 2. ed. Frankfurt: Suhrkamp.

. (1989a): Vorstudien und Ergänzungen zur Theorie des kommunikativen Handeins. 3. ed.

Frankfurt: Suhrkamp.

. (1990): “Soberania popular como procedimento: Um conceito normativo de espaço públi-

co". In: Novos Estudos, São Paulo, n. 26, p. 100-13, mar.

. (1991): "Que significa socialismo hoje? Revolução recuperadora e necessidade de revisão de

esquerda". In: Novos Estudos, São Paulo, n. 30, p. 43-61, jul.

HABERMAS, Jürgen et al. (1989): Tempo Brasileiro, (número especial: Jürgen Habermas, 60 anos), Rio de Janeiro, n. 98, jul.-set.

HINKELAMMERT, Franz J. (1984): Crítica a la razón utópica. San José: DEI.

MANNHEIM, Karl (1971): Ideologia e utopia. 2. ed., Rio de Janeiro: Zahar.

Kegan Paul.

(1982): Structures of thinking. (Editado por David Kettler et alii). London: Routledge and

McCARTHY, Thomas (1985): The critical theory of Jürgen Habermas. Cambridge: MIT Press. 
OLIVEIRA, Manfredo Araújo de (1988): Ética e religião. In: Revista Eclesiástica Brasileira, Petrópolis, n. 190, jun., p. 368-81.

. (1989): "A crise da racionalidade moderna: uma crise de esperança". In: Síntese, Belo Horizonte, n. 45, jan.-abr., p. 13-33.

RIRICOEUR, Paul (1986): Lectures on Ideology and Utopia. New York: Columbia University Press.

SIEBENEICHLER, Flávio Beno (1990): Jürgen Habermas: razão comunicativa e emancipação. 2. ed. Rio de Janeiro: Tempo Brasileiro.

THOMPSON, John B. e HELD, David (ed.) (1982): Habermas: Critical debates. Cambridge: MIT Press.

ZIMMERMANN, Roque (1987): América Latina: o não ser - Uma abordagem filosófica a partir de Enrique Dussel (1962-76). 2. ed. Petrópolis: Vozes. 